\title{
Outbound Chinese tourists: Understanding attitudes, constraints and information sources
}

\author{
Authors: \\ Professor Beverley Sparks, PhD \\ Tourism, Leisure, Hotel \& Sport Management \\ Griffith Business School \\ Griffith University \\ PMB 50, GCMC, 9726 \\ B.Sparks@griffith.edu.au
}

Dr Grace Wen Pan $^{1}$

Head, Travel and Leisure Research

ACNielsen China, the Nielsen Company

2/F, 618 Yan'an East Road

East Ocean Commercial Centre (II)

Shanghai, 200001, P.R.of China

Grace.Pan@nielsen.com

Acknowledgement: The Tourism, Sport and Service Innovation Research Centre provided support for this research.

Drawing upon Theory of Planned Behaviour a survey was developed and implemented in Shanghai, China to investigate potential outbound tourists' values in terms of destination attributes, as well as attitudes toward international travel. Five destination attributes were rated as most important by this potential group of tourists and included the natural beauty and icons of a destination, quality infrastructure, autonomy, inspirational motives and social self enhancement. In terms of predicting intentions to travel, social normative influences and perceived levels of personal control constraints were most influential based on TPB. The use of information sources in seeking information about a destination was also investigated. The evidence obtained suggests that television programs are an important source of information used by Chinese people to learn about target destinations. The role of the Internet as an information source was also shown to be substantial and stands to have a stronger impact over time.

Keywords: Chinese outbound tourists; attitudes; travel constraints; information sources; Theory of Planned Behaviour

\footnotetext{
${ }^{1}$ The research was undertaken when Dr Pan was employed at Griffith University
} 


\section{Background}

The Chinese population is growing in affluence, with outbound travel continuing to climb as more people can afford the luxury of tourism experiences. It has been predicted that outbound travel from China will grow to somewhere in the vicinity of 100 million by 2020 (World Tourism Organization, 2003). Despite this enormous potential, relatively little research has been conducted into the attitudes toward travel of potential outbound Mainland Chinese tourists. Some exceptions include outbound travel to Hong Kong, Taiwan, Malaysia, Singapore or Thailand (e.g. Cai, Boger \& O’Leary, 1999; Huang \& Hsu, 2005). Our paper, drawing upon attitudinal theory, collected data from potential Mainland Chinese outbound tourists in order to profile tourist preferences, beliefs, attitudes, constraints and sources of influence with a link to travel intentions. The target destination used for this research was Australia. Reasons for choosing Australia as a target destination for Chinese tourists are presented in the following section. The specific aims of the paper include: investigating a destination importance attitudinal model for Chinese tourists considering international travel; providing a comparison of the attribute importance model with belief perceptions of Australia as a destination; conducting an evaluation of information sources used by potential Chinese tourists; and investigating how information sources influence destination perceptions.

\section{Literature Review}

\subsection{Chinese tourists}

According to official figures, China had a population of 1.3 billion early in 2005 (Chinese Statistical Yearbook has the population for the end of 2004 at 1.29988 billion and the end of 2005 at 1.20756 billion). The opportunity for Chinese to travel outside Mainland China for 
leisure travel purposes is fairly recent. However, Chinese in the middle and top incomes are already starting to consider travel a 'birthright' (World Travel and Tourism Council (WTTC), 2006, p. 15) and there have been an increasing number of Chinese taking outbound trips (China National Tourism Administration, 2006). There is general agreement that the growth of China's economy is leading to a rapid increase in international travel from a burgeoning middle class. The Chinese Government loosened the restrictions on the outbound tourism market in 1983 with the introduction of the Approved Destination Status (ADS) scheme. ADS is an administrative measure by means of which the Chinese Government permits its residents to travel to selected countries for personal and leisure purposes, usually on allinclusive package tours. The number of ADS countries continues to expand for Chinese outbound tourists. By the end of 1 January 2008, the Chinese government had granted ADS to 92 countries, including the United States and Taiwan.

(http://www.cnta.gov.cn/zhuanti/cjy/index.asp). China has been recognized as one of two major emerging outbound tourism markets in the world (WTTC, 2006) and in 2007, 41 million Chinese engaged in outbound travel (China National Tourism Administration, 2006). There has been a growing interest in researching outbound Chinese tourists (e.g. Guo, Seongseop \& Timothy, 2007; Yu \& Weiler, 2001; Zhang, \& Heung, 2002). The current paper focuses primarily on those studies that relate specifically to destination image or attitudinal preferences of outbound Chinese.

\subsection{Australia as a destination for Chinese tourists}

Not surprisingly, China has been acknowledged as an important emerging market by the Australian inbound tourism industry. The number of Chinese arrivals to Australia has increased at an average rate of 25.9 percent each year since 1985, reaching 285,800 in 2005 
(Australian Bureau of Statistics, 2005). The Australian Tourism Forecasting Committee (2007) reported 308,000 Chinese tourist arrivals in 2006 and estimate this will increase to 1,016,000 arrivals in 2016. Past research (Kim, Guo \& Agrusa, 2005) has demonstrated that Australia is an attractive destination for outbound Chinese and that it is positioned quite differently from other closer Asian destinations, such as Japan, Singapore and South Korea. Australia is an appropriate target destination for this travel intention research for several reasons: it is culturally different from China, involving moderately long haul travel for Chinese tourists; it is ADS recognised by the Chinese government; and it is generally viewed as a desirable destination by Chinese tourists. As shown in Figure 1, of those destinations with ADS prior to the end of 2007, Australia was a Western country visited by outbound Chinese tourists as a first stop (China National Tourism Administration, 2007).

Insert Figure 1 about here

\subsection{Travel intentions}

The travel intentions tourists hold can be investigated by developing insight into issues such as perceptions or attitudes about a destination, as well as key influences, constraints and levels of perceived personal control over the resources required to achieve the target behaviour. Drawing on attitude theory (Fishbein \& Ajzen, 1975; Ajzen, 1991, 2001; Ajzen \& Fishbein, 2005), this paper seeks to strengthen the understanding of factors influential in determining Chinese tourist outbound travel and, more specifically, their travel to Australia as one of the Western ADS countries. 
The theory of planned behaviour (TPB) is an established theoretical model of explaining the relationship between consumers’ beliefs, attitudes, intentions, and behaviours (Ajzen, 1991, 2001). TPB has been applied in a variety of studies on social behaviour, including studies on the decisions of students completing high school (Davis, Ajzen, Saunders \& Williams, 2002), consumer choices of transportation mode (Bamberg, Ajzen \& Schmidt, 2003), the influence of negative word-of-mouth on Chinese consumers' intention of choosing restaurants to dine at (Cheng, Lam \& Hsu, 2006) and, attitudes toward wine tourism (Sparks, 2007). Similarly, TPB has been applied to assist in explaining consumers’ complex travel decision-making process (Lam \& Hsu, 2006). For example, Hsu, Kang and Lam (2006) examined reference groups' influences on Chinese travellers travel intentions, and Lam and Hsu (2006) applied TPB to study intentions of Taiwanese travellers choosing Hong Kong as a travel destination. Lam and Hsu (2006) found that TPB provided a good model fit for potential Taiwanese travellers to Hong Kong. Their research emphasised the importance that factors like social influence and perceived behavioural control play for this group. Thus, we argue that attitudinal theory provides a sound foundation to understanding travel intentions of tourists and underpins the research presented in this paper.

By way of a brief overview of TPB, Figure 2 depicts the basic framework usually applied in such studies. Ajzen (2008 a) argues that TPB provides a sound basis to predict behaviour by understanding three discrete belief categories. Beliefs about some target behaviour (such as travelling to a specific destination) as well as an evaluation of these beliefs; beliefs about the normative expectations of others (e.g. family, friends) as well as a desire to comply with these expectations; and beliefs about factors that might facilitate or impede the target behaviour (e.g. available funds to travel) as well as the ability to deal with these potential 
impediments. Each of these categories of beliefs has subsequent implications: behavioural beliefs influence attitudes toward the behaviour; normative beliefs lead to social pressures (subjective norms); and constraint or control beliefs contribute to an overall evaluation perceived behavioural control. In many TPB studies, behavioural intention is taken as a proxy measure of likely behaviour. Ultimately, there are three direct predictors of behavioural intention: attitude, subjective norm and perceived control, which form the core of the TPB model.

Insert Figure 2 about here

In evaluating behavioural intentions it is possible to use the direct measures of attitude, subjective norm and perceived control. In addition, it is possible to provide insight into the foundation of each of these three predictors by also collecting information about the indirect or underlying measure of attitudes, subjective norms and perceived control, as shown in Figure 2.

\subsection{Destination attributes}

As outlined, beliefs about target behaviour are the precursor to attitudes and can assist in providing detailed insight to the attitudes in question. In consumer behaviour, it is recognised that most consumption decisions will involve the evaluation of a range of product attributes when making a purchase decision. That is, a consumer will form evaluative beliefs about a product based on a variety of attribute features. Similarly, any evaluation of potential travel destinations is also likely to involve a multi-attribute belief assessment of the destination. In tourism, research has demonstrated destination attributes of beautiful landscape, shopping 
opportunities, cultural exchange, infrastructure (e.g. accommodation, dinning), safety issues and activities are often important in defining the image of the destination (see for example, Chi \& Qu, in press; Echtner \& Ritchie, 1991; 1993). The wide range of destination literature (see for example, Echtner \& Ritchie, 1991;1993; Kim, Guo \& Agrusa, 2005; Pike, 2002; Stepchenkova \& Morrison, 2008) is generally in agreement that any evaluation of a tourist destination will be multi-dimensional. Developing an understanding of both the importance of destination attributes in general, as well as salient beliefs a target market, such as the Chinese, hold about a specific destination provides potentially useful information in attitude formation. As mentioned, this dual focus on beliefs and importance (values), which has had wide recognition in consumer behaviour research, is often referred to as an expectancy-value approach (Ajzen, 2008).

Fishbein and Ajzen (1975) define attitude toward an object as an individual's positive or negative feelings (evaluation) about the target behaviour. The overall evaluation of a destination is likely to be central to any intentions to visit the destination. It is assumed that the attitudes toward travelling to a destination will be determined by the key importance/belief attributes of the destination. Thus, as suggested by TPB, certain destination attributes will drive intended behaviour. First, attitude will be influenced by the evaluation of key destination features (expectancy-value dimensions) and will, in turn, influence intention to engage in such behaviour. In terms of key destination attributes that are likely to be attractive to outbound Chinese tourists, work by Kim, Guo and Agrusa (2005) reported the five top destination attributes as safety, beautiful scenery, well equipped tourism facilities, different cultural / historical resources and good weather. Perception of any target tourist destination on key attributes will, of course, be influential in determining an overall 
preference, or otherwise, for that destination. How such perceptions are formed are also of interest to this research and one route may be through the sources of information available to potential tourists. The present research seeks to extend the TPB by including a further understanding of how information might shape the beliefs potential tourists hold.

\subsection{Information sources and image}

Research has determined that various forms of information play a role in determining destination image (Baloglu \& Mc Cleary, 1999; Tasci \& Gartner, 2007). Potential tourists have a myriad of information sources available when investigating where to travel. Sources of information are varied and, therefore, likely to comprise both organic (self experience or non-commercial sources) and induced (advertiser message derived) (see Tasci \& Gartner, 2007) components. Past research by Fodness and Murray (1998; 1999) has cited information sources such as brochures, friends/relatives, car clubs and personal experience as being highly ranked by tourists, although which sources are used depends on phase of travel (prepurchase or at destination). Similarly, tourism research (e.g. Beerli \& Martin, 2004) has provided evidence that word of mouth derived from sources such as friends or family can be influential in the formation of some components of image perceptions of a destination. The variety of information sources continues to expand with increasing access to lifestyle media (e.g. travel television shows) and Internet. Of interest to our research are information sources being used by potential outbound Chinese tourists and whether these information sources are related to target destination perceptions/beliefs. Thus, we extend the TPB model to incorporate the assertion that information sources will influence the beliefs formed about he destination. 


\subsection{Influences and constraints}

The TPB predicts that there is a range of factors that can potentially influence or constrain travel intentions. More specifically, what others think or do (often referred to as subjective norms) as well as constraints or barriers, and the control over constraints or barriers (Ajzen, 1991) have the potential to impact travel intentions. First, intentions to travel are likely to be influenced by what others, who form a reference group for the consumer, think or do in regard to the target behaviour. TPB predicts that when a subjective norm is favourable then so is the intention to engage in the behaviour. Relevant tourism research (Lam \& Hsu, 2006) found subjective norms to be an important factor in influencing Taiwanese tourists' intentions to visit Hong Kong. Similarly, Hsu, Kang \& Lam, (2006) found reference group influences to be important in determining travel behaviour of outbound Chinese travellers. Based on past research (e.g. Hsu et al. 2006), for potential Chinese tourists, the types of normative pressures are most likely to include that from friends, family, or travel agents.

It is also recognised that there may be a range of constraints that impede or prevent someone from travelling outside of China. For Chinese tourists, factors such as language, distance, cost or Government control (e.g. obtaining a visa) might be some such impediments.

Overcoming such constraints or having a feeling of a sense of perceived control over the target behaviour is also likely to be important in determining travel intentions. Ajzen (1991) has pointed out that control beliefs can obstruct or make possible a particular behaviour. A consumer's perceptions of having or not having the resources (e.g. time or money) to engage in specific travel behaviour will impact travel intentions. Perceived control has been identified as an important construct for predicting intention to visit a tourist destination (see, Lam \& Hsu, 2006; Sparks, 2007). Similarly, leisure researchers have identified structural 
barriers such as time, financial resources, season, climate or family life cycle that can inhibit participation in certain activities (Crawford, Jackson \& Godbey, 1991). For Chinese tourists, key constraints could include the currency exchange rate of the Yuan, cost of travel, perceptions of safety in travel, length of travel time and Government visa restrictions.

In summary, the key questions to be investigated in this research were:

What attributes of international destinations are important to Chinese outbound travellers? What beliefs about destination attributes do potential outbound travellers hold about Australia and how do these compare to importance evaluations?

How do these belief evaluations impact the formation of attitude toward a destination? What information sources are used by potential outbound travellers and how do these influence the beliefs held about the target destination?

What attitude, influence, constraint and control factors impact a potential traveller's intention to travel to the target destination?

\subsection{The study}

This paper makes four major contributions to the literature: (1) it extends a destination importance attitudinal model (TPB) for Chinese tourists considering international (outbound) travel, (2) it provides a comparison of the attribute importance model with belief perceptions of Australia as a destination, (3) it presents an evaluation of information sources used by potential Chinese tourists and (4) it investigates how information sources influence destination perceptions. Figure 3 presents a conceptual overview of the variables investigated in this study.

Insert Figure 3 about here 


\subsection{Method}

The study design employed a survey approach to test an established theoretical model in the Chinese outbound tourist context. Past research has shown that the measurement model of TPB is able to transfer and be reliably applied to the Chinese context (e.g. Bagozzi, Lee \& Van Loo, 2001; Chan \& Lau, 2001; Lam \& Hsu, 2006). To ensure the questionnaire items were relevant to the target sample, the authors discussed with expert personnel (e.g. travel agents, tourists) the types of beliefs, norms and constraints that would be most appropriate for Chinese outbound tourists. A small pilot study was also undertaken to clarify the coverage of the constructs in the model.

\subsection{Sample}

This study used a convenience sample of 548 potential tourists from Mainland China. All respondents were selected from Shanghai and the selection of this city is justified for three reasons. First, Shanghai is frequently described as China’s most sophisticated, highly educated and prosperous city. Second, most outbound tourists are from the more affluent cities like Shanghai, Beijing or Guangzhou. Finally, access through one of the author's networks in Shanghai assisted in accessing respondents. All respondents were residents of Shanghai and $62 \%$ were male.

\subsection{Instrument}

A questionnaire self-report survey was developed with the aim of measuring a range of TPB variables relevant to Chinese consumers' views toward international travel, with an emphasis on Australia as the target destination. First, to enable the testing of TPB, overall or global 
constructs were designed for directly measuring attitude toward the target behaviour, subjective normative influences, perceived behavioural control and behavioural intention. Next, a range of belief based measures were designed as indirect measures of each of attitude, subjective norm and control. In addition, we also sought to measure the use of information sources as a possible precursor to the attitudinal beliefs. Finally, a range of demographic and travel behaviour questions were asked for profiling purposes.

\section{Direct measures of TPB}

As mentioned, it is possible to test TPB with the direct measures of attitude, subjective norm and perceived control. This section describes the measurement of each of these (see also Table 1).

Insert Table 1 about here

\section{Attitude measure}

In line with TPB, overall attitudinal evaluation of the specific destination was measured using six statements. Each statement used a semantic differential response scale: “All things considered, taking a holiday to Australia in the next 12 months would be ...” unenjoyable/ enjoyable, bad/good, foolish/ fun, unpleasant/ pleasant, unfavourable/ favourable, disliked/ liked. Each was measured on bipolar scales where 1 was the negative end of the scale and 7 was positive.

\section{Subjective normative influence}


Statements used to measure subjective normative influence were measured on a Likert type scale from 1 (strongly disagree) through to 7 (strongly agree). Four statements measuring subjective normative influence (family or reference group) relevant to making travel decisions were included (Ajzen, 2001). Sample items include: "Friends and family have recommended I take a holiday to Australia in the next 12 months”, "I would like to visit Australia within the next 12 months because I have heard a lot about this destination from friends and family”.

\section{Perceived behavioural control}

In line with TPB, perceived behavioural control in relation to taking a holiday to Australia was measured using three statements: "I feel I have enough money to take a holiday to Australia in the next 12 months”, "I feel I have enough time to take a holiday to Australia in the next 12 months" or "I feel there is nothing that prevents me from taking a holiday to Australia in the next 12 months if I want to”. Each was measured on a Likert type scale from 1 (strongly disagree) through to 7 (strongly agree).

\section{Behavioural Intention}

Behavioural intention to visit Australia was measured using two items that required responses on a five-point scale $(1=$ very unlikely and $5=$ very likely $)$. The items were worded as follows: "How likely would you be to take a holiday to Australia within the next 12 months?" and "I intend to take a holiday to Australia within the next 12 months".

\section{Underlying beliefs of the model}


In addition to the direct measures, our research sought to investigate the underlying beliefs of attitude, subjective norms and perceived control. We also sought to measure information sources as a precursor to beliefs about the destination.

\section{Beliefs about the destination}

As part of developing a deeper understanding of the beliefs that could drive outbound tourist attitudes we also measured a range of destination attributes using an expectancy-value approach. Thus, to measure the more specific predictors of behavioural intentions and image formation, a range of questions were formulated. First, respondents were asked their evaluations of the importance (value) of overseas holidays. The importance of taking an international holiday was measured using 50 destination attributes, which were developed based on attributes identified primarily by past researchers (e.g. Echtner \& Ritchie 1991;1993). Respondents were requested to rate the level of importance they ascribed to each attribute on a scale of one to five, where one meant "not important at all” and five meant “most important”. Following the importance evaluations, respondents were asked to evaluate the same attribute as a likelihood belief statement (expectancy) about a specific target destination, in this case Australia (that is, their belief as to the likelihood that Australia would offer the attribute). The statements were rated on a five-point scale, where 1 was labelled “least likely” and 5 was labelled “most likely”.

\section{Information sources}

As an extension to the research model, we also sought to better understand what might be shaping the beliefs statements. As a result, information sources used in finding out about tourism destinations were also measured (expanded from Fodness \& Murray, 1998). 
Respondents were asked to indicate whether or not they had used various sources to find information about Australia as a target destination. First, respondents indicated on a dichotomous scale (yes/no) whether they had used the information source; then they were asked to rate the importance of the source for themselves $(1=$ very unimportant and 5 = very important). A total of 17 sources were included, such as travel books, travel brochures, websites, on-line chat-rooms, television, radio, word of mouth and personal experiences.

\section{Beliefs about subjective norms}

Four statements measured the normative beliefs in relation to possible referent others (such as family, travel agent). These were measured on a Likert type scale from 1 (strongly disagree) through to 7 (strongly agree), for example, "My travel agent thinks I should take a holiday in Australia within the next 12 months”. Finally, four items measuring a willingness to comply with the social influences were also included (e.g. Generally speaking, I want to do what most members of my family think I should do, 1 (strongly disagree) through to 7 (strongly agree).

\section{Beliefs about potential constraints or control}

Based upon research and information elicited through the pilot discussions of outbound travel by Chinese, ten belief statements covered a range of possible constraints to visiting the target destination including "The flight time it takes to get to Australia makes it difficult for me to take a holiday there within the next 12 months" or "Language barriers do not make it difficult for me to travel to Australia in the next 12 months" (reverse scored). Each was measured as follows: 1 (strongly disagree) through to 7 (strongly agree). 


\subsection{Procedure}

The questionnaire was written in English and then translated to Mandarin by a professional translator. A back translation approach was then undertaken to ensure that the language and its meaning were consistent. The Mandarin version of the questionnaire was also pilot tested on a group ( $\mathrm{N}=50)$ of Chinese postgraduate students studying in Australia. The aim of the pilot test was to check the clarity of the wording in the Mandarin version of the questionnaire, thus ensuring correspondence to the intended English meaning. One of the authors, who is native Mainland Chinese, also discussed with the pilot study group the questions in terms of clarity of meaning and coverage. Many of the constraint items were elicited as a result of this initial planning phase. Minor adjustments were made to any items lacking clarity.

Data collection for the main study took place in Shanghai in July 2006. The research was conducted in line with ethical guidelines of the authors' host university; all participants were provided with the project information brief. The researcher (one of the authors), who was located at a large travel agency, approached everyone who made an enquiry about travelling outside of China. The purpose of the research was explained, and potential participants were asked to indicate their willingness to fill out a questionnaire about travel. All respondents were recruited on a voluntary and anonymous basis. Those who filled out the questionnaire were given a small token of appreciation from Australia on completion of the task as a gesture to thank them for their cooperation. Those customers who agreed to participate were handed a self completion questionnaire together with an envelope and asked to respond while at the travel agency and return the questionnaire to a specified place.

\subsection{Results}




\subsection{Sample Characteristics}

The demographic profile of the sample is outlined in Table 2. Approximately $60 \%$ of respondents were young singles under the age of 35 or young couples without children. Most (80.8\%) had received a qualification from a university. Occupations were diverse with a large proportion (74.4\%) of respondents having professional careers as white-collared workers, teachers, businesspersons, civil servants and senior managers. The reported gross monthly household income reported by $67 \%$ of the respondents was less than 8,000 Yuan (equivalent to approximately AUD \$1,333 or USD \$1003 at the time of the survey). More than one fifth (22.8\%) of the respondents who earned less than 8,000 Yuan, and over half (51.2\%) of the respondents who earned more than 8,000 Yuan, confirmed their likelihood of taking a holiday outside mainland China within the next 12 months.

Insert Table 2 about here

\subsection{Travel behaviour profile}

More than half of the respondents reported taking a holiday outside China less than once a year, and over one fourth (28.5\%) reported taking an outbound holiday once a year. It seems that most overseas holidays reported by respondents tend to be short with the majority (89.8\%) taking two weeks or less for holiday outside of China. Two thirds of the respondents had made outbound trips, among which one fourth (24.7\%) have made three or more outbound trips.

Insert Table 3 about here 
Two thirds (63.3\%) of respondents indicated that they preferred packaged tours (including both fully and partially packaged) than individual tours. Fully packaged tours were the most preferred type of travel for more than one third of respondents (39.3\%). However, it seems that for this sample of respondents, that there is a notable portion that has an inclination toward individual tours (35.7\%) and partially packaged tours (25.0\%). Around two thirds of the respondents who take short breaks and one week holidays reported using fully or partially packaged tours, however, when taking a longer holiday, such as two weeks holiday, $51 \%$ of respondents preferred individual travel.

\subsection{Countries and regions by visits}

Hong Kong was reported to be the most popular destination with nearly half of the respondents (47.8\%) having been to Hong Kong, followed by Macau and South East Asian countries, which are the pioneering countries granted ADS status by the Chinese Government. Europe has the largest proportion (14.2\%) of visits among the list of Western ADS regions, followed by Australia and New Zealand.

\subsection{Application of TPB}

To test the TPB model we used the direct measures of attitude, subjective normative influences and perceived control to predict the behavioural intention of visiting Australia. Table 1 shows the items for each scale. In each case the respective items measuring each construct were summed and averaged into one scale (see Table 1 for the reliability and descriptive statistics). 
A standard regression analysis was conducted with the direct measures of attitude, subjective norm influences and perceived control as predictors and the rating for likelihood of travelling to Australia as the dependent variable. The equation was significant, $F(3,417)=49.7, \mathrm{p}<$ .001 , with the set of three factors explaining 26\% (adjusted) of the variance in likelihood to travel (see Table 4). Subjective norm influences and perceived control were significant predictors but attitude was not (although attitude did have a positive and significant correlation with behavioural intention $(\mathrm{r}=.150, \mathrm{p}=.001)$. In particular, it seems potential tourists who felt that (a) others thought they should take a holiday to Australia (social influences were high) and (b) they had sufficient resources (time and money), were more likely to indicate that they intend to travel to Australia. This finding lends support to TPB but shows the Chinese sample is influenced more by subjective norms and perceived control than attitudes.

Insert Table 4 about here

\subsection{Further investigation of the beliefs underlying attitude, subjective norms and} control

As mentioned, the TPB allows for researchers to also investigate the underlying beliefs of the direct measures tested in the above analysis. Next, we investigate each of the underlying sets of beliefs for attitude, subjective norm and perceived control. We also investigate the role of information sources in the formation of beliefs about the destination.

\subsubsection{An expectancy-value belief understanding of Chinese tourists' attitudes towards outbound travel destinations}


Underlying the attitude toward behaviour is the expectancy-value beliefs held by the target group. As there were a large number of destination attribute items surveyed in the study, a data reduction process of factor analysis was applied. The 50 items representing evaluations of importance toward tourism destination attributes were analysed using Principal Component Analysis. This analysis was conducted in order to summarise the patterns of interrelations among the large set of attributes by reducing the number of items into a smaller set of relatively homogenous “factors”.

The correlation matrix was examined prior to the initial factor analysis. Items were examined for very low $(r<.35)$ or very high $(r>.9)$ correlations. This led to the removal of one item "Museum and Gallery”. Several iterations of the factor analyses were then conducted and their solutions were examined. In each analysis, the communalities table was examined and any item with a communality of $<.50$ was removed. The Bartlett's test of sphericity and the KMO measure of sampling adequacy were also checked and both were adequate in all analyses. Only factors with an eigenvalue of $>1$ were interpreted. Items were retained if they loaded at .5 or more on a factor and did not load at more than .4 on any two factors.

The results for the final solution with a varimax rotation are reported in Table 5. For this final solution the KMO measure of sampling adequacy was .884 and the Bartlett's Test of Sphericity was significant $(\mathrm{p}<.001)$. The analyses revealed nine factors with eigenvalues $>1$. These factors accounted for $66.95 \%$ of the total variance. Composite variables were constructed in SPSS for each of the nine destination importance dimensions, based on a summation of the item scores and division by the number of items. Scale reliability tests were conducted for each factor revealing Cronbach’s Alphas between 0.752 and 0.890 . 
Insert Table 5 about here

As indicated in Table 5, two factors, natural beauty and climate and infrastructure at the destination, received the highest mean importance ratings. The item pertaining to safety of the destination attracted the highest importance rating (4.14 out of 5) in the infrastructure factor. Autonomy at the destination was also rated highly. The attribute dimension of local culture and novel experiences received the lowest rating, 2.97 out of 5 in destination factors.

\subsubsection{Difference between importance and beliefs}

Based on the factor analysis of the importance dimensions, composite scores were constructed for the corresponding belief scales. We were interested to determine if there were any significant differences between the importance ratings and the beliefs Chinese tourists held about the likelihood that the same dimension would be evident on a trip Australia (see Table 5 for means). A paired sample $t$-test was conducted to examine the differences on each of the factors. To control for Type 1 error Bonferroni correction was applied, $p<.005$. An effect size for each $t$-test result was calculated by converting the $t$-value to an $r$-value (Field, 2005). The effect is considered small where $r=.10$, medium where $r=.30$ and large where $r$ $=.50$. The results indicate that for the dimensions of infrastructure $(t(404)=11.42, p<.005$, $r=.24)$, natural beauty $(t(345)=6.46, p<.005, r=.11)$, inspiration $(t(427)=8.07, p<.005$, $r=.13)$, social $(t(422)=7.50, p<.005, r=.12)$, interacting with locals $(t(402)=5.58, p<$ $.005, r=.07)$, and autonomy $(t(429)=10.70, p<.005, r=.21)$ the importance mean is significantly higher than the corresponding likelihood belief. In contrast, for the dimensions 
of local culture $(t(400)=-4.03, p<.005, r=.04)$ and shopping $(t(432)=-3.53, p<.005, r=$ .03) the likelihood mean exceeded the importance mean.

To test which of the factor dimension beliefs about Australia as a tourist destination predicted overall attitude to travel to Australia we conducted a multiple regression with the nine belief scales as predictors. The equation was not significant. Next, we used a summated scale of the beliefs by importance ratings to investigate the association with attitude, correlation analysis showed a significant relations $\mathrm{r}=.331, \mathrm{p}<.001$.

\subsubsection{Chinese social demographic differences for the destination factors}

A series of cross-tabulations, ANOVAs and t-tests were run on the nine importance factors to determine any differences according to respondents’ social demographic information. Of those tests, significant results for life stage indicate that mature tourists (age 35+ without children, including empty nesters) rated natural beauty and climate of higher importance than did younger respondents (under 35) or families $(M=4.31,4.01$, 3.98 respectively, $F=3.2$, p $=.04$ ). Younger respondents (under 35) rated local culture and novel experiences as more important than did families or mature tourists $(M=3.13, \mathrm{M}=2.77, M=2.54$, respectively, $F$ $=11.7, \mathrm{p}<.001)$. An investigation of age, irrespective of family life stage, revealed that younger and middle age people rated autonomy as more important than did the mature age group (55 plus) ( $M=4.03, M=3.91, M=3.47$, respectively, $F=4.79, p=.009$ ). How much experience people had with international travel was also significant. Those who were classified as experienced travellers (i.e. those who have travelled internationally three times or more) rated infrastructure $(M=4.24)$ at the destination as more important than did less 
experienced travellers (travelled internationally less than three times) ( $M=3.98, F=7.30, p$ $=.007)$. There were no gender differences.

\subsubsection{Destination information sources}

An aim of the study was to discover the information sources used by potential tourists and the connection between these information sources and beliefs about the destination. Respondents were asked about the information sources that they used (if any) to form an image of what Australia has to offer a tourist. As illustrated in Figure 4, television programs were most often used in collecting information about a destination, with more than half (60\%) of respondents finding information on Australia as a destination from this source. Similarly, gathering information from friends (57\%) was also reported to be an important source of information as were fashion magazines and travel books, with 54\% of respondents learning about Australia as a destination through these media. About half (49\%) of Chinese consumers found destination information on Australia from Chinese websites, and one third of respondents used online chatting to find destination information.

Insert Figure 4 about here

\subsubsection{Connection between information sources and destination image assessments}

For those information sources used by more than $50 \%$ of the respondents, we investigated links between the source and beliefs about Australia as a destination. Several multiple regressions were run with the top six information sources (measured on an importance scale) as predictors and each of the destination's attribute belief dimensions as a criterion in separate equations. Only four significant relationships were found. Television was significant 
in predicting the following belief attributes: inspiration $(\beta=.20)$, social $(\beta=.23)$, interaction with locals ( $\beta=.19)$ and shopping $(\beta=.22)$. The information source of friends was significant in predicting perceptions of natural beauty $(\beta=.23)$.

Finally, we also tested whether a prior visit to the target destination made any difference to the beliefs held about the target destination; no significant differences emerged.

\subsubsection{Normative beliefs and willingness to comply}

Underlying the subjective norms are the normative beliefs held by the motivation to comply (see Table 6). The referent groups used in this study included family, friends, co-workers and travel agents. For each referent group the item measuring the normative belief was multiplied by the motivation to comply to form a new item (scores could range from 1 to 49). Mean scores were ranked from highest to lowest, family $(\mathrm{M}=17.17)$, friends $(\mathrm{M}=16.38)$, co-workers $(\mathrm{M}=15.65)$ and travel agents ( $M=14.33)$, respectively. We also investigated any gender differences and found significant male/female differences for all referent groups apart from family, see Table 7. In general, females reported higher levels of normative influence than did males. The largest difference was for co-worker, whereby females report higher levels of influence than did males. A simple regression showed that the item 'normative beliefs by motivation to comply' was a significant predictor (beta .74) of subjective norm (F 535.67, p < .001 , adj $\left.\mathrm{R}^{2} .55\right)$.

Insert Table 6 \& 7 about here

\subsubsection{Constraints to travel}


Underlying perceived control is a range of possible constraints that may hinder achieving the target action (see Table 6). Two dimensions were shown to exist and these comprised 'external factors' and 'safety factors'. External factors were rated as a moderate influence on barriers to travelling to Australia. Safety was rated positively with Australia seen a relatively safe destination and, thus, a minor barrier to travel. A multiple regression showed that the two constraint dimensions were significant predictors (external barriers, beta .20; safety, beta .45 ) of perceived control (F 83.17, $\mathrm{p}<.001$, adj $\left.\mathrm{R}^{2} .27\right)$.

\subsection{Discussion}

This study sought to gain a deeper awareness to how attitudes, constraints, influences and information sources are related to the intentions of potential Chinese tourists to travel outside their homeland and, in particular, to Australia. The study helps to fill a gap in understanding outbound Chinese tourists while testing an attitudinal model.

\subsection{Overview of findings}

A test of the TPB model showed it is a useful theoretical approach for investigating behavioural intentions. The subjective norm measure, which is based on social influences, had a strong association with behavioural intention. Similarly, perceived control was also correlated with, and predictive of, behavioural intention. However, attitude towards taking a holiday at the destination was not significant in predicting intentions to take a holiday in Australia. As Ajzen (2008 b) asserts there is nothing in TPB to say attitudes, subjective norms and perceived control all need to make a significant contribution to behavioural intention. Rather, for certain behaviour or groups it may be that the relative importance of the three categories of predictors can vary. It seems that, for this sample, the effects of social 
influences and perceived control are stronger predictors than are attitudes. Our findings were similar to those reported by Lam and Hsu (2006), whereby attitude seems to have little impact on travel intentions. Thus, it might well be that for travel behaviour, prospective tourists place a greater importance on social norms or perceived control factors than attitudes. It seems the Chinese sample is more likely to intend to visit the target destination when other people like friends, family, co-workers or travel agents think it is a positive thing to do. It appears reference groups are influential in travel intentions for the Chinese. This is consistent with other tourism related work that established the importance of reference groups in travel behaviour (see for example, Hsu, Kang \& Lam, 2006; Sparks, 2007). It is also consistent with cross-cultural attitude work whereby Bagozzi et al (2001) found Chinese behavioural intention to be more influenced by social norms and less influenced by attitudes than Americans. Similarly, Chan and Lau (2001) found that social norms were weighted heavier than attitudes in predicting behavioural disposition for Chinese consumers. The collectivist nature of the Chinese culture might also explain the strength of social influences in stated behavioural intentions. Interestingly, it seems that, apart from family influences, females are more likely to feel the social pressures of reference groups than males.

Perceived control over a range of relevant factors is also important when determining behavioural intentions. The present study sought to expand the range of potential barriers and control over these as part of the study's contributions. It was found that having the resources in terms of time and money is a significant factor in determining whether someone intends to visit the target destination. Other external constraints in terms of exchange rates, travel distance and language issue were associated with perceived control. 
Nine destination factors were identified based upon Chinese respondents' considerations of the factors that are important when taking a holiday overseas. These nine destination importance factors were compared to beliefs about a specific ADS destination, namely Australia. The importance factors provide useful information, from the consumer perspective, to take into account when destinations decide 'to brand' or 'not to brand' in their effort to draw more Chinese tourists, to encourage them to stay longer, and spend more money during their visit. The five attributes rated as most important by this potential group of tourists included the natural beauty and icons of a destination, quality infrastructure, autonomy, inspirational motives and social self enhancement. The target destination (Australia) varied in its ability to match the importance scores on some dimensions with infrastructure, natural beauty, inspiration, social, interacting with locals and autonomy falling short of the importance evaluations. In contrast, perceptions of the target destination exceeded the corresponding importance rating on potential to offer a unique local culture and shopping opportunities. Somewhat surprisingly, the individual beliefs held about the target destination had no significant effect on the overall attitude held towards taking a holiday at the destination. However, the overall additive effect of beliefs did have a significant correlation with attitudes. The lack of a strong finding for beliefs and attitude suggests that more work needs to be done to better understand the application of research models derived from Western countries to Chinese tourists.

In respect of information sources, the evidence obtained from the present study suggests that television programs play an important role in how Chinese people learn about target destinations. Interestingly, this medium was also associated with beliefs formed about the target destination (Australia), namely: (1) how inspiring it is, (2) the opportunity for social 
self enhancement, (3) the prospect of interacting with locals, and (4) shopping opportunities. The importance of television is consistent with Gover, Go and Kumar's (2007) work on the relationship between information sources and destination image, in which they found television to be the most frequently mentioned information source. Also in line with Gover et al's research friends and magazines were highly used sources. One point of difference from Gover and his colleagues is in relation to personal travel experience, which was quite low in the present study mainly because the sample had little direct experience with the target destination. The Chinese sample also reported fairly high levels of Internet use as a way of sourcing information about the target destination, using both Chinese and Australian web sites. The information source of friends was influential in predicting the image held about the target destination in terms of natural beauty and climate. This is somewhat similar to Beerli and Martin’s (2004) finding that friends and family influenced tourists' beliefs about the atmosphere of the destination.

\subsection{Managerial implications}

Several practical implications arose from the research, and these may be of interest to destination managers or marketers. First, at a more general level, the younger generation demonstrated somewhat different importance evaluations from the rest of the respondents towards travelling overseas. It seems that the new generation of travellers, young singles (under age 35), are potentially a more ‘showy' generation who are more 'adventurous' than mature respondents (age 35+). They would like to explore new things, as well as seek and talk about new experiences with their friends. This is the upcoming generation who will become the main Chinese travel market. Targeting this new generation will need to be quite different from the current destination marketing approach. 
This study demonstrates the changing characteristics of Chinese consumers. This reflects not only on their changing life style, but also the information sources they use to find information about destinations. Fashion magazines exceed the 'traditional' medium, the newspaper, for the respondents in this study to find destination information on Australia. It is estimated that, in 2007, there are approximately 162 million Chinese online, i.e. $12.33 \%$ of the total population in China and this number is growing daily (China Internet Network Information Center, 2007). Importantly, many towns of county level and above throughout China have internet cafes. Thus, people can get online whether they have their own facilities or not. As a result, it is likely that online chatting will become an important information source for Chinese consumers. In the present study, around one third of the respondents indicated online chatting was a source of destination information.

Within the destination dimension of infrastructure, the item of safety was highly rated by the respondents. This finding is consistent with the recent study on Asia Travel Intentions Survey (ACNielsen, 2006) where 82\% of Chinese tourists were found to have safety and security concerns when travelling to other Asian countries. It seems that Chinese tourists are highly safety conscious, and they may not be willing to take risks in travelling to places perceived to be dangerous. Hence, safety assurance is recommended when marketing to Chinese tourists. Overall, $60 \%$ of the respondents consider that safety and security at the destination are important and Australia was seen as a relatively safe destination. Inspirational motives and social/self enhancement were among the nine importance factors when taking a holiday overseas that Chinese tourists regarded as at least moderately important. 
The finding that most Chinese tourists report taking a 'short' holiday is consistent with the limited annual leave Chinese residents have depending on the nature of companies, hence shorter or week long holidays are preferred by most Chinese tourists. Most Chinese take holidays during the three so-called Golden Weeks public holiday periods.

The results of the present study suggest that there is a trend for younger Chinese to want more autonomy during their travel, possibly having flexible time to explore the destination rather than "hopping on and off a coach" with a packed and tightly organised itinerary. It seems evident that Chinese tourists travel behaviour and life style are changing, and is particularly so for the younger generation.

This study also reaffirmed other studies demonstrating the importance of subjective normative influences. Managers should consider the importance of advertising that draws on positive associations with relevant reference groups like family, friend and co-workers. Furthermore, the recognition that females might be more readily influenced by some groups could assist in targeted marketing.

\subsection{Limitations and future directions}

This study provided unique insights into to a group of potential Chinese tourists by drawing on TPB constructs and applying these to travel intentions. The findings provide results consistent with the TPB model, however, like most studies, it is not without limitations. First, the sample was conveniently derived from one city (Shanghai) and it is quite possible that Chinese in other cities such as Beijing could hold different beliefs. Future research should attempt to obtain samples from other major cities that have the potential for outbound travel. It must be recognised that the sample is not necessarily representative of all outbound 
Chinese travellers as reliance on one travel agent site was applied in this study. Second, the sample was biased towards young people and it would be preferable to gain the views of a broader range of age groups. Future research could attempt to stratify the sample by age to obtain insight into the likely generational change in attitudes toward outbound travel. Third, comparative studies using samples from a range of countries would also add to the findings so that the Chinese sample could be compared to other international samples. Fourth, this study adopted a more positivist deductive approach to the design. The use of adapted construct measures provides the advantage of being reliable and valid in the countries the scales are developed but may not transfer to other cultures. As research on Chinese tourists is relatively immature it may be important to investigate topics, such as the one reported here, from a more exploratory inductive approach (see Ryan, Huimin \& Wei, forthcoming). In so doing it is possible that the range of items used to explain intentions could differ from TPB or at least enhance the items used to represent the various constructs. Similarly, theoretically approaches other than TPB could be adopted, especially in respect of focussing less on individual beliefs and more on group oriented constructs. In terms of other future research, legislation changes are constantly evolving and warrant monitoring for research opportunities. For example, Chinese incentive travel now allows groups to travel overseas, thus making this travel market a potential "hidden dragon”. Research into destination choice for incentive travel relevant to the Mainland Chinese market is warranted. 


\section{Reference List}

ACNielsen, (2006). Asia Travel Intentions Survey. Retrieved 2 July 2008, http://www.pata.org/patasite/fileadmin/news_pata/060425_ASIA_TRAVEL_INTENTIONS_ SURVEY_FINAL.pdf.

Ajzen, I. (1991). The Theory of Planned Behavior. Organizational Behavior and Human Decision Processes, 50, 179-211.

Ajzen, I. (2001). Construction of a Standard Questionnaire for the Theory of Planned Behavior, Retrieved February 2006 from http://www.people.umass.edu/aizen/pdf/tpb.measurement.pdf

Ajzen, I. (2008a). Consumer attitudes and behavior. In C. P. Haugtvedt, P. M. Herr \& F. R. Cardes (Eds.), Handbook of Consumer Psychology (525- 548). New York: Lawrence Erlbaum Associates.

Ajzen, I. (2008b). Theory of planned behavior. Retrieved June 3, 2008, from http://www.people.umass.edu/aizen/faq.html .

Ajzen, I., \& Fishbein, M. (2005). The Influence of Attitudes on Behavior. In D. Albarracín, B. T. Johnson \& M. P. Zanna (Eds.), The Handbook of Attitudes (pp. 173-221). Mahwah, NJ: Erlbaum.

Australian Bureau of Statistics (2005). Overseas Arrivals and Departures (3401.0). Canberra. Bamberg, S., Ajzen, I. \& Schmidt, P. (2003). Choice of Travel Mode in the Theory of Planned Behaviour: The Roles of Past Behaviour, Habit, and Reasoned Action. Basic and Applied Social Psychology, 25 (3), 175-187.

Bagozzi, R. P., Lee, H. M., Van Loo, M. F. (2001). Decisions to donate bone marrow: The role of attitudes and subjective norms across cultures. Psychology and Health, 16, 29-56. 
Baloglu, S. \& Mc Cleary, K. W. (1999). A model of destination image formation. Annals of Tourism Research, 26, 868-897.

Beerli, A. \& Martin, J. D. (2004). Factors influencing destination image. Annals of Tourism Research, 31, 657-681.

Cai, L. A., Boger, C. \& O’Leary, J. (1999). The Chinese travelers to Singapore, Malaysia and Thailand: A unique Chinese outbound market. Asia Pacific Journal of Tourism Research, 3 (2), 2-13.

Chan, R. Y. K. \& Lau, L. B. Y. (2001). Explaining green purchasing behaviour: A cross cultural study on American and Chinese consumers. Journal of International Consumer Marketing, 14 (2/3) 9-40.

Cheng, S., Lam, T., \& Hsu, C. H. C. (2006). Negative Word-of-Mouth Communication Intention: An Application of the Theory of Planned Behaviour. Journal of Hospitality \& Tourism Research, 30 (1), 95-116.

China Internet Network Information Center: 20th Statistical Survey Report on the Internet Development in China. (January 2007), downloaded January $17^{\text {th }} 2008$ http://www.cnnic.cn/download/2007/cnnic19threport.pdf

China National Tourism Administration (2007). ADS first stop in Nielson PATA Travel Mart Bali September 2007.

China National Tourism Administration (2006).

http://www.cnta.gov.cn/zhuanti/cjy/index.asp

Chi, C. G. \& Qu, H. (2008). Examining structural relationships of destination image, tourist satisfaction and destination loyalty: An integrated approach. Tourism Management, 29 624-636. 
Crawford, D. W., E. L. Jackson, and G. Godbey (1991). A Hierarchical Model of Leisure Constraints. Leisure Sciences, 13, 309-20.

Davis, L. E., Ajzen, I., Saunders, J. \& Williams, T. (2002). The Decision of African American Students to Complete High School: An Application of the Theory of Planned Behaviour. Journal of Educational Psychology, 94 (4), 810-819.

Echtner, C. M. \& Ritchie, J. R. B. (1991). The meaning and measurement of destination image. Journal of Tourism Studies, 2 (2), 2-12.

Echtner, C. M. \& Ritchie, J. R. B. (1993). The Measurement of Destination Image: An Empirical Assessment. Journal of Travel Research, 31 (4), 3-13.

Fishbein, M., \& Ajzen, I. (1975). Belief, Attitude, Intention, and Behavior: An Introduction to Theory and Research. Reading, MA: Addison-Wesley.

Fodness, D. and Murray, B. (1998). A typology of tourist information search strategies. Journal of Travel Research, 37 (2), 108-119.

Fodness, D. and Murray, B. (1999). A model of tourist information search behaviour. Journal of Travel Research. 37, 220-230.

Gallarza, M. G., Gill Saura, I. \& Calderón Garcia, H. (2002). Destination Image: Towards a Conceptual Framework. Annals of Tourism Research, 29 (1), 56-78.

Govers, R, Go, F. M. \& Kumar, K. (2007). Promoting tourism destination image. Journal of Travel Research, 46, 15-23.

Guo, Y., Seongseop, K. \& Timothy, D. J. (2007). Development characteristics and implications of Mainland Chinese outbound tourism. Asia Pacific Journal of Tourism Research, 12 (4), 313-332. 
Hsu, C. H. C., Kang, S. K. \& Lam, T. (2006). Reference Group Influence among Chinese Travellers. Journal of Travel Research, 44, 474-484.

Huang, S. \& Hsu, C. H. C. (2005). Mainland Chinese residents' perceptions and motivations of visiting Hong Kong: Evidence from focus group interviews. Asia Pacific Journal of Tourism Research, 10 (2), 191- 205.

Kim, S. Guo, Y. \& Agrusa, J. (2005). Preference and positioning analyses of overseas destinations by Mainland Chinese outbound pleasure tourists. Journal of Travel Research, 44, 212-220.

Lam, T. \& Hsu, C. H. C. (2006). Predicting behavioral intention of choosing a travel destination. Tourism Management, 27, 589-599.

Mayo, E. J. \& Jarvis, L. P. (1981). The psychology of leisure travel. Boston: CBI.

Pike, S. (2002). Destination image analysis - a review of 142 papers from 1973 to 2000. Tourism Management, 23, 541-549.

Ryan, C., Huimin, G. and Wei, Z. (Forthcoming). The context of Chinese tourism - an overview and implications for research. In Chris Ryan and Huimin Gu. (eds.) Tourism in China: Destinations, Culture and Communities. Routledge, New York.

Stepchenkova, S. \& Morrison, A. M. (2008). Russia’s destination image among American pleasure travellers: Revisiting Echtner and Ritchie. Tourism Management, 29, 548-560. Sparks, B. A. (2007). Planning a wine tourism vacation? Factors that help to predict tourist behavioural intentions. Tourism Management, 28, 1180-1192.

Tasci, A. D. A. \& Gartner, W. C. (2007). Destination image and its functional relationships. Journal of Travel Research, 45 (40), 413-425.

World Tourism Organization. (2003). Chinese Outbound Tourism. Madrid. 
World Travel and Tourism Council (2006). China, China Hong Kong and China Macau. Retrieved 3 July 2008

http://www.wttc.org/eng/Tourism_Initiatives/Regional_Initiatives/China/Launch_of_China_ Report_2006/

Yu, X \& Weiler, B. (2001). Mainland Chinese pleasure travellers to Australia: A leisure behaviour analysis. Tourism, Culture \& Communication, 3, 81-91.

Zhang, H. Q. \& Heung, V. C. S. (2002). The emergence of the Mainland Chinese outbound travel market and its importance to tourism. Journal of Vacation Marketing, 8 (7), 7-12. 
Table 1 Items for direct measurement of TPB

\begin{tabular}{lc}
\hline Items $^{a}$ & $\begin{array}{c}\text { Cronbach } \\
\text { Alpha }\end{array}$ \\
\hline Attitude toward travel to Australia (Mean $=5.69$, SD = 1.34) & .95 \\
\hline Unenjoyable/Enjoyable & \\
Bad/Good & \\
Foolish/Fun & \\
Unpleasant/Pleasant & \\
Unfavourable/Favourable & \\
Dislike/Like &
\end{tabular}

Subjective normative influences $($ Mean $=4.02, S D=1.35)$

I would like to take a holiday in Australia within the next 12months because it is popular among my friends or family

People who are important to me would probably think it would be good to take a holiday in Australia within the next 12 months

Friends or family have recommended I take a holiday to Australia

within the next 12 months

I would like to visit Australia within then next 12 months because I

have heard a lot about this destination from friends or family

Perceived control $($ Mean $=3.92, S D=1.37)$

I feel I have enough time to take a holiday to Australia within the next

12 months

I feel I have enough money to take a holiday to Australia within the next 12 months

I feel there is nothing that prevents me from taking a holiday to

Australia within the next 12 months if I want to

Behavioural intention $^{b}($ Mean $=2.75, S D=0.89)$

I intend to take a holiday to Australia within the next 12 months How likely would you be to take a holiday to Australia within the next 12 months?

${ }^{\mathrm{a}}$ Measured on 7 point scale ${ }^{\mathrm{b}}$ Measured on 5 point scale 
Table 2 Sample characteristics

\begin{tabular}{|c|c|c|c|}
\hline \multirow{2}{*}{$\begin{array}{l}\text { Sample Characteristic } \\
\text { Employment status }(n=496)\end{array}$} & $\%$ & Sample Characteristic & $\%$ \\
\hline & & \multicolumn{2}{|l|}{ Education $(n=514)$} \\
\hline Full-time & 81.0 & High school or below & 18.3 \\
\hline Part-time & 5.2 & University/college degree & 68.7 \\
\hline Not employed & 1.4 & Postgraduate degree & 12.1 \\
\hline Retired & 5.2 & Other & 1.0 \\
\hline Self-employed & 4.2 & & \\
\hline Other & 2.8 & & \\
\hline Household gross monthly income $(n=514)$ & & Occupation $(n=510)$ & \\
\hline Less than 5,000 & 32.9 & Civil servant & 7.1 \\
\hline $5,001-8,000$ & 34.8 & Businessperson & 9.0 \\
\hline $8,001-10,000$ & 13.6 & Teacher & 12.4 \\
\hline $10,001-15,000$ & 7.6 & Clerk/white-collar worker & 41.4 \\
\hline $15,001-20,000$ & 4.7 & Blue-collar worker & 6.1 \\
\hline $20,001-30,000$ & 1.9 & Senior manager & 4.5 \\
\hline \multirow[t]{3}{*}{30,0001 and above } & 4.5 & Retired person & 4.5 \\
\hline & & Student & 12.2 \\
\hline & & Other & 2.9 \\
\hline Life stage $(n=500)$ & & Gender $(n=520)$ & \\
\hline Young singles (under age 35) & 53 & Male & 61.5 \\
\hline Young couple (under age 35) & 9 & Female & 38.5 \\
\hline Family with children at home & 24.4 & & \\
\hline Mature singles (age 35+) and empty nesters & 13.6 & & \\
\hline
\end{tabular}


Table 3 Travel behaviour patterns

\begin{tabular}{|c|c|c|c|}
\hline Sample Travel Pattern & $\%$ & Sample Travel Pattern & $\%$ \\
\hline $\begin{array}{l}\text { Frequency of taking a holiday overseas } \\
(n=505)\end{array}$ & & Preferred types of holiday $(n=538)$ & \\
\hline & & Individual & 35.1 \\
\hline Less than once a year & 57.0 & Fully packaged tour & 38.8 \\
\hline Once a year & 28.5 & Partially packaged tour & 24.5 \\
\hline Twice a year & 6.9 & Other (please specify) & 1.5 \\
\hline Three times a year & 1.6 & & \\
\hline Other (please specify) & 5.9 & & \\
\hline Length of overseas trips $(n=502)$ & & Number of overseas trips $(n=542)$ & \\
\hline Short break (3-4 days) & 30.1 & 0 & 33.2 \\
\hline One week & 38.2 & 1 & 22.0 \\
\hline Two weeks & 21.5 & 2 & 20.1 \\
\hline Three Weeks & 4.6 & 3 & 12.5 \\
\hline One week and two weeks & 1.8 & 4 & 3.0 \\
\hline Other (please specify) & 3.8 & 5 or more & 9.2 \\
\hline
\end{tabular}

Note: Overseas trips include Hong Kong and Macau. 
Table 4 Regression analysis to test TPB using direct measures of attitude, subjective norm and perceived control

\begin{tabular}{lccc}
\hline Variables in regression equation & B & SE B & $\beta$ \\
Constant & 1.38 & .17 & \\
Attitude & -.005 & .03 & -.008 \\
Subjective normative influences & .21 & .03 & $.33^{* * *}$ \\
Perceived control & .16 & .03 & $.25^{* * *}$ \\
\hline & $R^{2}=.26$, adjusted $R^{2}=.26, * * * \mathrm{p}<.001$.
\end{tabular}


Table 5 Factor loading for importance attributes and mean comparison with target destination beliefs

\begin{tabular}{lccccc}
\hline Factor & $\begin{array}{c}\text { Factor } \\
\text { Loading }\end{array}$ & $\begin{array}{c}\text { \% } \\
\text { Variance } \\
\text { Explained }\end{array}$ & $\begin{array}{c}\text { Cronbach's } \\
\text { Alpha }\end{array}$ & $\begin{array}{c}\text { Mean } \\
\text { importance } \\
\text { rating }\end{array}$ & $\begin{array}{c}\text { Mean } \\
\text { perception } \\
\text { of Australia }\end{array}$ \\
\hline Infrastructure at the destination & & 25.08 & 0.89 & $4.05(.89)$ & $3.49(.94)$
\end{tabular}

Quality of accommodation $\quad 0.84$

facilities

Quality of services provided at $\quad 0.80$

tourist sites and hotels

Safety of the place $\quad 0.78$

Natural beauty and climate

$11.30 \quad 0.856 \quad 4.05(.77) \quad 3.60(1.06)$

Natural environment of fresh air $\quad 0.81$

and blue sky

Sunshine

0.79

Unique architecture

0.64

Local culture and social

7.59

0.858

$2.97(.96)$

$3.19(.92)$

characteristics

Casino

0.73

Nightlife and evening

0.72

entertainment

Western food

0.69

Inspirational motives

5.88

0.844

$3.82(.81)$

$3.45(.94)$

A change from my daily routine $\quad 0.74$

An opportunity to feel inspired

0.74 
pressure and stress

Social/self enhancement

A new experience that I can talk

0.74

about with my friends

An opportunity to visit a place that

0.64

my friends and relatives have not

been

The opportunity to strengthen my

0.57

family member/co-worker ties

Interactions with locals

Ease of communication with locals

0.78

Willingness of providing

0.66

information to Chinese tourists

Opportunity to visit friends and

0.61

relatives

\section{Sightseeing spots}

Botanical gardens

0.83

Theme parks

0.80

Aquariums

0.79

\section{Shopping}

Shopping for souvenir and gifts

0.82

Shopping for local special products
4.19

0.833

$3.63(.87)$

$3.28(.94)$ 
Shopping for brand name products

Autonomy

Plenty of time to myself outside

the itinerary

Plenty of time to take photos
0.68

2.75

0.752

$3.98(.79)$

$3.50(.97)$

0.60 
Table 6 Items for underlying beliefs for normative influence and perceived control

Items

Alpha

Normative belief by motivation to $\operatorname{comply}^{\mathrm{a}}($ Mean $=15.80, S D=$

Most of my co-workers think I should take a holiday in Australia

within the next 12 months BY Generally speaking, I want to do what

my co-workers think I should do

My travel agent thinks I should take a holiday in Australia within the next 12 months BY Generally speaking, I want to do what my travel agent think I should do

Most of my friends think I should take a holiday in Australia within the next 12 months BY Generally speaking, I want to do what most of my close friends think I should do Most of my family think I should take a holiday in Australia within the next 12 months BY Generally speaking, I want to do what most members of my family think I should do

External barriers constraint beliefs ${ }^{\mathrm{b}}(\mathrm{Mean}=3.66, \mathrm{SD}=1.37)$

The exchange rate for Chinese Yuan to Australian dollar would prevent me from going to Australia within the next 12 months The flight time it takes to get to Australia makes it difficult for me to take a holiday there within the next 12 months 
Media warnings about travel to Australia would not prevent me from visiting Australia within the next 12 months

The cost of travelling to Australia would prevent me from going within the next 12 months Language barriers do not make it difficult for me to travel to Australia within the next 12 months There is high risk associated with travelling to Australian within the next 12 months News on the relationships between the Chinese and Australian Governments would directly impact on decisions of visiting Australia within the next 12 months VISA regulations do not present a barrier to me travelling to Australia for a holiday within the next 12 months

Safety constraints ${ }^{\mathrm{b}}($ Mean $=4.47, S D=1.25)$

Compared to travelling to other countries, Australia is low risk All things considered, travelling to Australia within the next 12 months would be a safe choice

${ }^{a}$ Based on multiplication of norm by motivation to comply. Highest possible score would be 49. ${ }^{\mathbf{b}}$ Measured on 1 strongly disagree to 7 strongly agree 
Table 7 Referent group influences ${ }^{\mathrm{a}}$

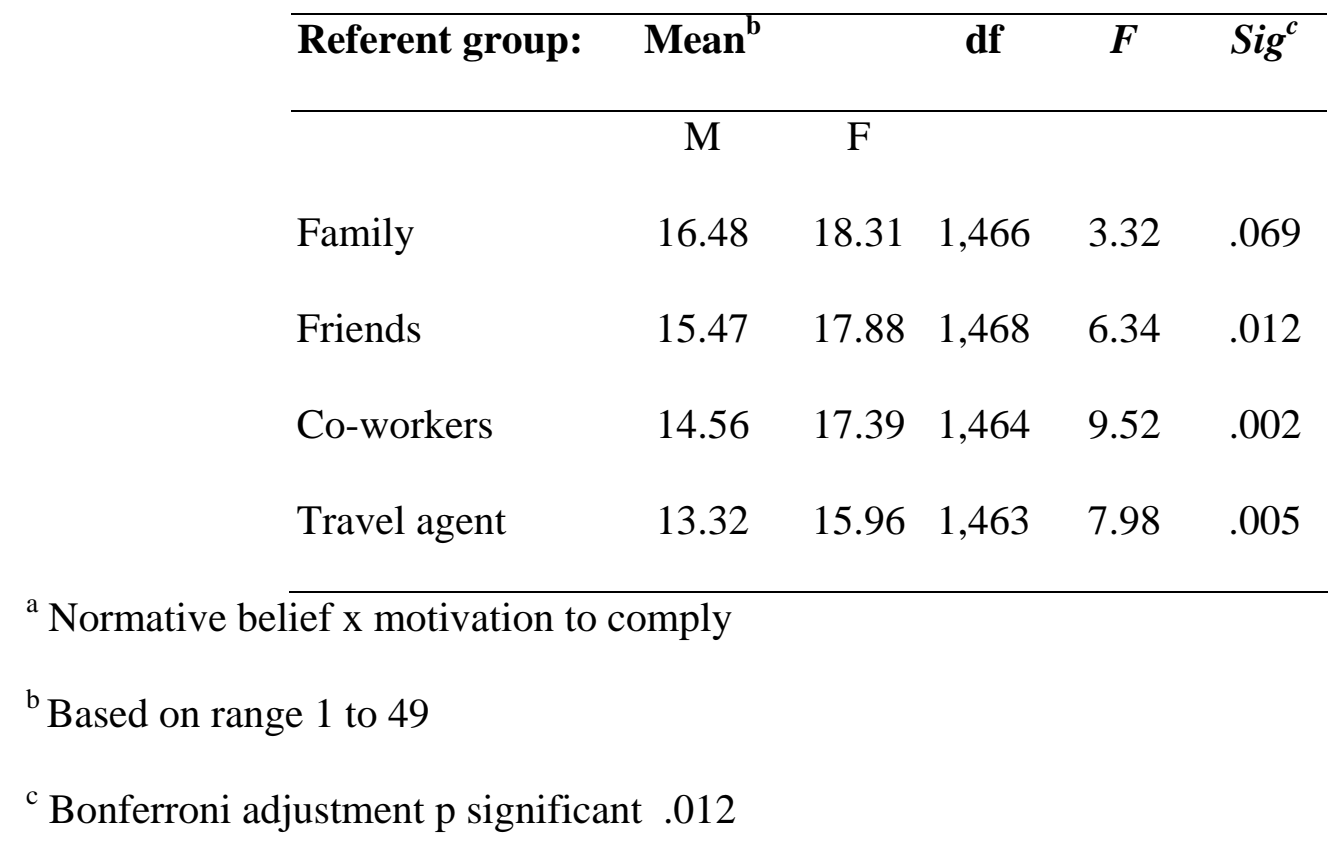




\section{Trips to ADS Destinations as the First Stop}

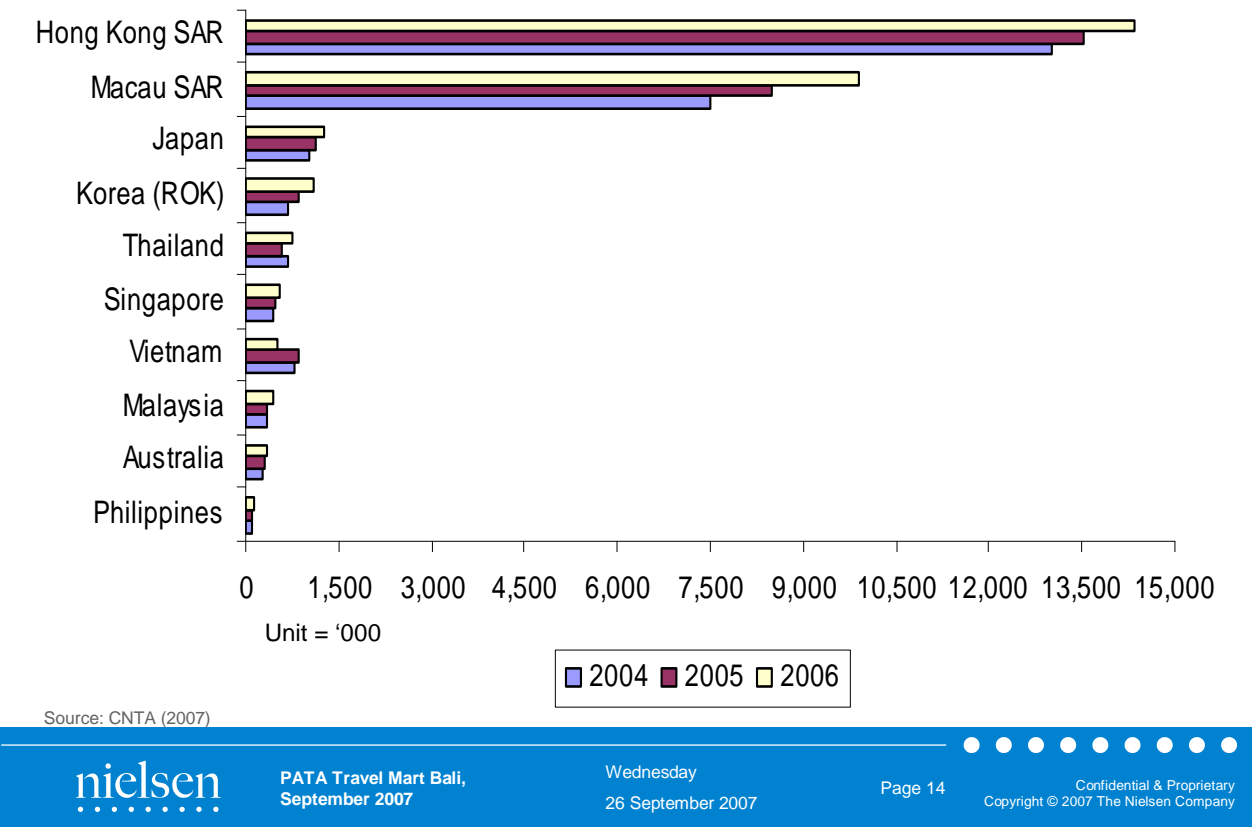

\section{Figure 1 ADS destinations and first stops}




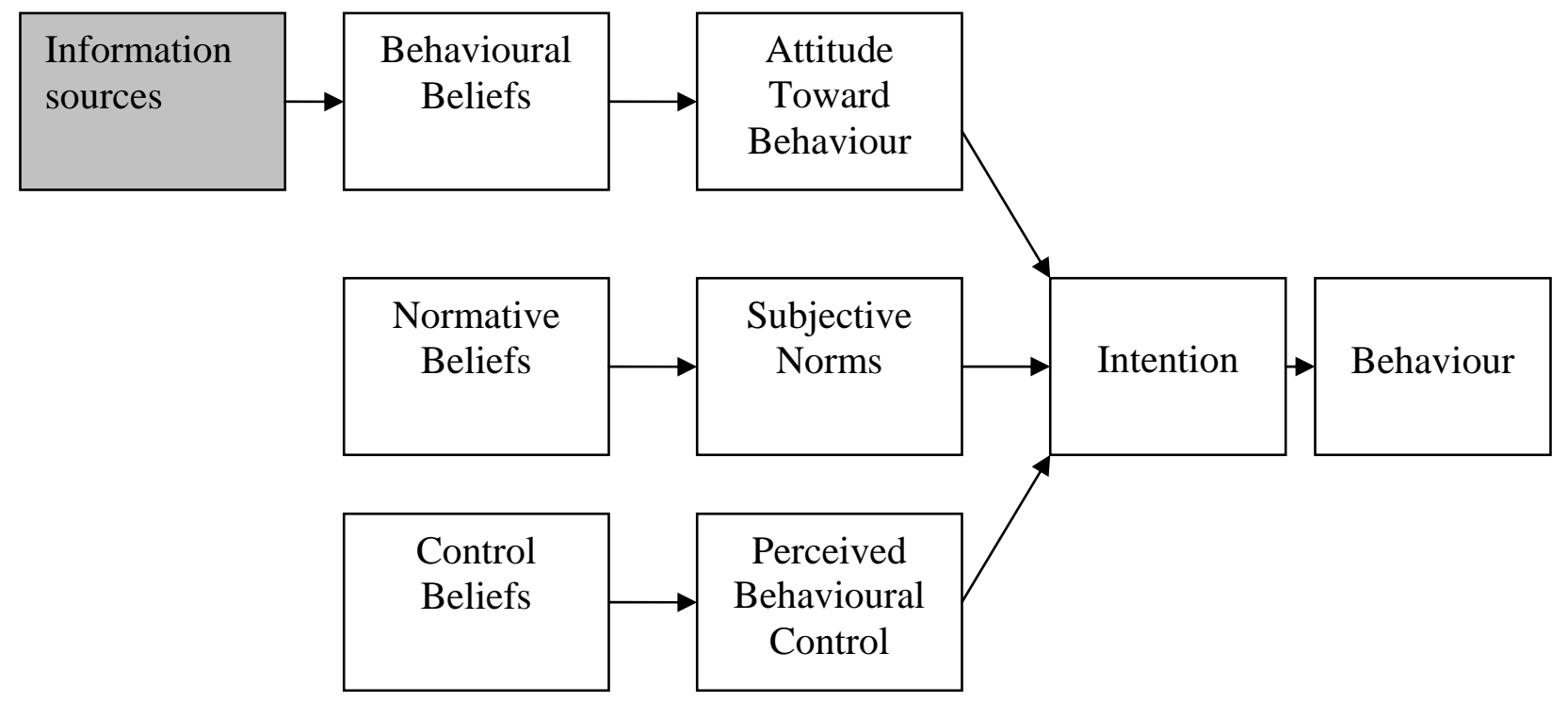

Figure 2: Schematic representation of TPB (after Ajzen, 2006 http://www.people.umass.edu/aizen/tpb.diag.html) 


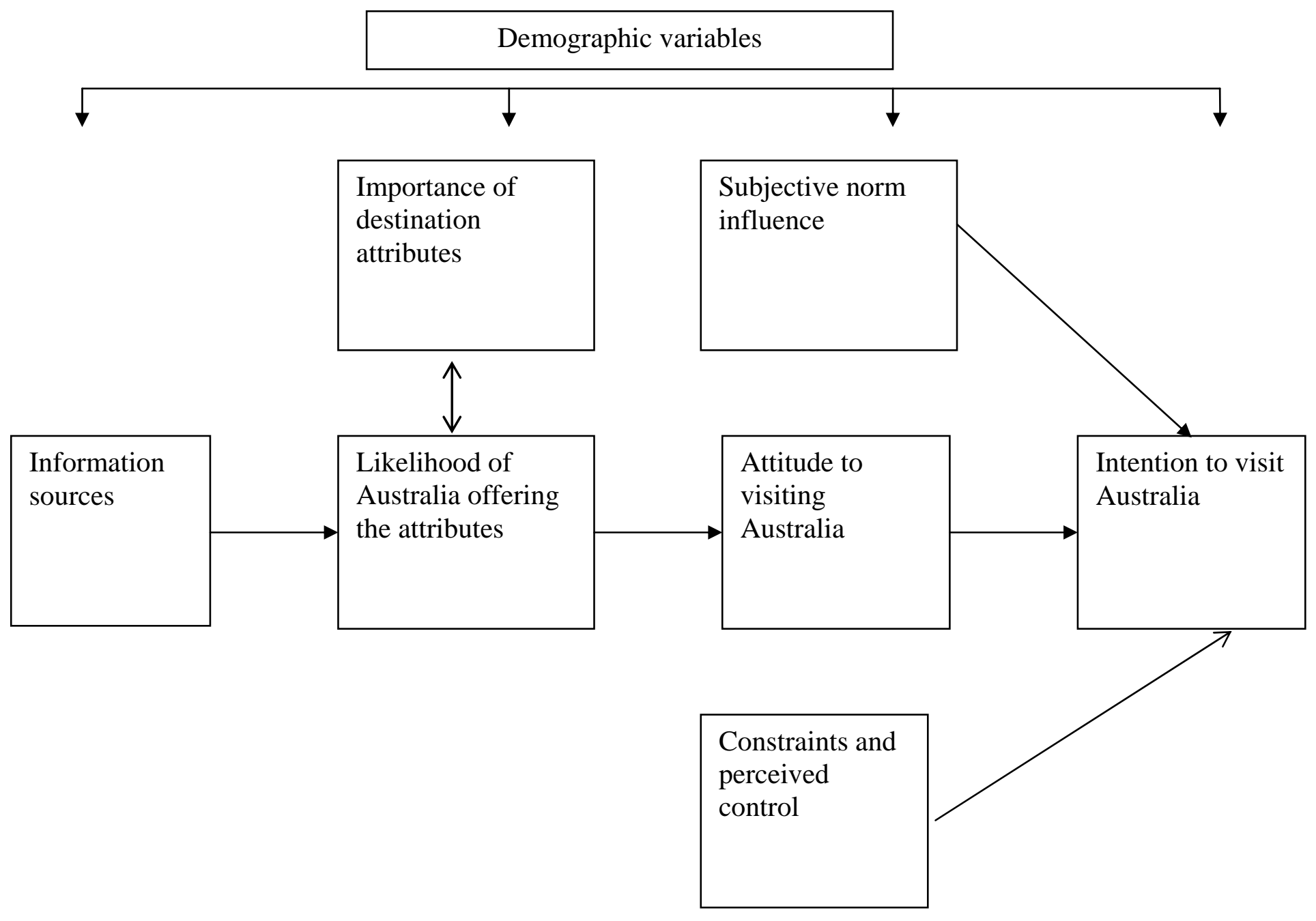

Figure 3 Conceptual overview of the study variables 


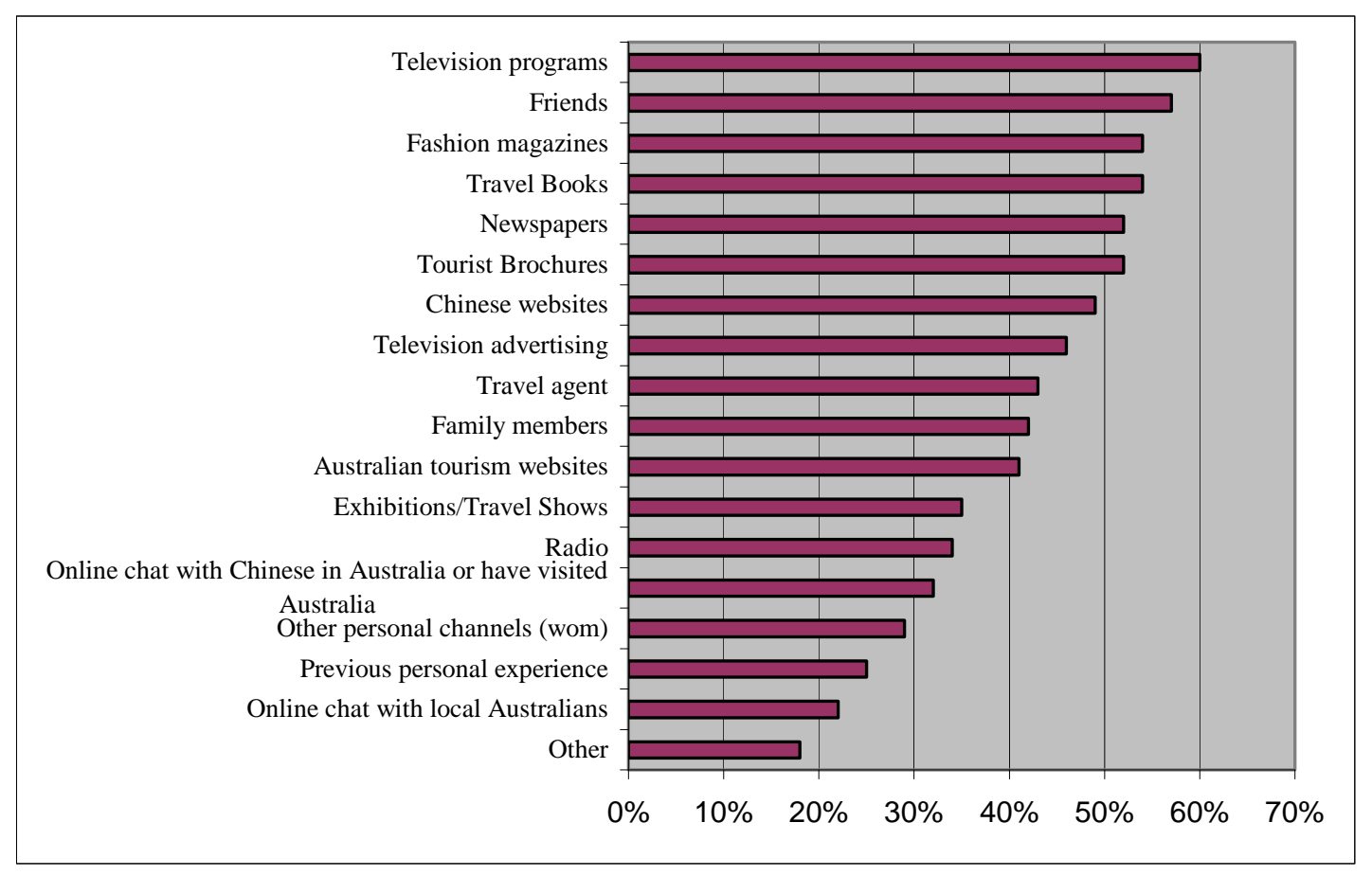

Figure 4 Use of information sources to find out information about target destination 